Evidence that maternal infection with Listeria may be a cause of abortion has come from several other sources. Gray et al. (1955) produced abortions in pregnant does by intraocular infection with Listeria. They also showed that pregnancy appears to predispose to infection with Listeria, since after oral challenge of pregnant rabbits the bacteria could be isolated from the vagina, but this was not the case with non-pregnant animals. Further evidence in humans has come from Seeliger (1958), who found that $16 \%$ of the mothers who gave birth to infants infected with Listeria had a history of previous abortions or stillborn infants. Rost et al. (1958) found that many women with a history of abortion had a high circulating antibody titre to Listeria monocytogenes and also that after antibiotic treatment the women gave birth to healthy full-term infants. These findings and those of other investigators are discussed by Gray (1960), who points out that further studies using a satisfactory isolation technique (see McBride and Girard, 1960) might indicate a high incidence of Listeria in the human genital tract. The single negative study in Britain (Macnaughton, 1962) of 78 women with threatened or incomplete abortion is not necessarily conclusive, since the technique of isolation differed in certain respects from that of Rappaport et al. (1960).

\section{Summary}

A bacteriologically proved case of listeriosis in both mother and prematurely born infant is recorded for the first time in Britain.

A review of the literature indicates that in some parts of the world not only is neonatal listeriosis relatively common but genital listeriosis may be a significant cause of repeated abortion.

Since Listeria monocytogenes is both difficult to obtain in primary culture and easily confused with a skin-contaminating diphtheroid, it is suggested that the low incidence of infection in Britain may be at least partly due to failure to recognize the condition.

We are grateful to our clinical colleagues at this hospital and Dr. E. P. Sullivan, of the Western Hospital, for permission to

\title{
Diverticulum of the Female Urethra
}

\author{
J. H. N. FERRIS,* M.A., M.B., M.A.O., M.R.C.O.G.
}

Diverticulum of the female urethra is a comparatively rare condition. Few cases have been described until the last decade. Pinkerton (1956) attributed this fact to a failure to stress its existence in undergraduate systematic lectures and clinical instruction. Few references to cases in England and Ireland exist (Lane, 1957 ; Hennessy, 1958 ; Felming, 1959 ; Frith, 1960), the total in Ireland being only 17 . One feels, however, that the sparsity of case reports may well be explained by a lack of interest to record such cases as well as the failure to diagnose this condition, which, although less common in these islands, is not so rare as is generally believed.

The diagnosis and treatment of three cases by me prompted this brief review of the condition.

* Senior Obstetrical Registrar, Jubilee Maternity Hospital, Belfast. publish the case and for supplying us with clinical details. We are also grateful to Dr. B. L. Murphy, of the Group Laboratory, St. Stephen's Hospital, for sending us a report of the necropsy on the baby.

\section{REFERENCES}

Barrow, G. I., and Pugh, R. J. (1958). 7. Path. Bact., 75, 9.

Beck, A. (1961). 7. clin. Path. 14, 512

- (1935). F. Bact., 30, 573

- (1936). Amer. Y. Path., 12, 341

Dungal, N. (1961). Lancet, $2,513$.

Edmunds, P. N., Nicholson, D. N., and Douglas, D. M. (1957). Brit. med. F., 2, 188 .

Gibson, H." J.' (1935). F. Path. Bact., 41, 239.

Girard, K. F., and Gavin, W. F. (1957). Ibid., 74, 93

Gray, M. L. (1951). F. Amer. vet. med., 118, 242. (1960). Lancet, 2, 315. (1958). Zh. Mikrobiol. (Mosk.), (English translation), 29, 1372.

Harding, J. W., and Brunton, G. B. (1962). Lancet, 2, 484 .

Hugh, R., and Leifson, E. (1953). \%. Bact., 66, 24

Johnston, W. H., Morton, S. A., Wong, M. H., and Roy, T. E. (1955). Canad. med. Ass. 7., 73, 402 .

Line, F. G., and Cherry, W. B. (1952). 7. Amer. med. Ass., 148, 366.

McBride, M. E., and Girard, K. F. (1960). A. Lab. clin. Med., 55, 153.

McKinnon, D., and Swithinbank, J. M. (1961). Lancet, 2, 516.

Macnaughton, M. C. (1962), Ibid., 2, 484.

Moore, S., and Whitmore, D. N. (1960). Brit. med. 7., 2, 1572.

Murray, E. G. D. (1955). Canad. med. Ass. Ұ., 72, 99.

Webb, R. A., and Swann, M. B. R. (1926). \%. Path. Bact., 29, 407.

Nyfeldt, A. (1937). Hygiea (Stockh.), 99, 433.

Olding, L., and Philipson, L. (1960). Acta path. microbiol. scand., 48, 24.

Paterson, J. S. (1940). 尹. Paih. Bact., 51, 427.

Pirie, J. H. H. (1927). Publ. S. Afr. Inst. med. Res., No. 20, iii, 163.

Potel, J. (1950-1). Zbl. Bakt., i56, 490

Potel, (1958). Zbl. Vet.-Med." Beiheft., i, 70.

Rappaport, F., Rabinovitz, M., Toaff, R., and Krochik, N. (1960). Lancet, 1, 1273.

Ray, C. G., and Wedgwood, R. J. (1964). Pediatrics, 34, 378.

Rost, H. F., Paul, H., and Seeliger, H. P. R. (1958). Dtsch. med. W schr., 83, $1893,1934$.

Schmidt, V., and Nyfeldt, A. (1938). Ugeskr. Lag., 100, 336.

Schultz, E. W., Terry, M. C., Brice, A. T. jun., and Gebhardt, L. P. (1933-4). "Proc. Soc. exp. Biol.' (N.Y.), 31, 1021.

Seeliger, H. P. R. (1958). Listeriose. Barth, Leipzig.

and Cherry, W. B. (1957). Report to U.S. Dept. of Health, Education and Welfare.

Toaff, R., Krochik, N., and Rabinovitz, M. (1962). Lancet, 2, 482.

Webb, R. A. (1943). Ibid., 2, 5.

and Barber, M. (1937).' f. Path. Bact., 45, 523.

Wramby, G. O. (1944). Scand. vet. T., 34, 277.
Burn, C. G. (1933-4). Proc. Soc. exp. Biol. (N.Y.), 31, 1095

(1963). Amer. F. publ. Hlth, 53, 554.

Gudkova, E. I., Mironova, K. A., Kus'minskii, A. S., and Geine, G. O. A.

A married woman aged 39 had a six-year history of recurrent cystitis and had had two uncomplicated confinements. She was referred to the gynaecological registrar by a surgical colleague after prolonged and unsuccessful investigation and treatment of her urinary complaint.

She complained of a severe pain in the vagina, intermittent for at least six years. This was more severe one week before and after menstruation. Frequency and urgency of micturition, together with pain in the vagina during micturition, were also frequent symptoms, as was deep dyspareunia. All these symptoms had recurred often despite treatment. Intravenous pyelography in 1959 and 1961, cystoscopy in 1959 and 1961, and urethroscopy in 1961 were all normal. Coliform urinary infection had been treated on four occasions. 
The patient was in a very distressed condition when she attended the gynaecological department because of the persistent pain in her vagina. Abdominal examination revealed a vague tenderness in the suprapubic region, but otherwise no abnormality. Vaginal examination showed the vulva to be normal, but on inspection of the anterior vaginal wall there appeared to be an indefinite swelling to the left of the upper third of the urethra. Palpation confirmed the presence of a tender fluctuant swelling, and the differential diagnosis of urethral diverticulum or periurethral abscess was considered. A micturating cystogram confirmed the diagnosis of urethral diverticulum (Fig. 1). A catheter specimen of urine was sterile.

The patient was admitted for surgery. At operation a diverticulum $3 \mathrm{~cm}$. in diameter was dissected free and excised. The ostium was closed and the wound sutured in two layers. An indwelling catheter was placed in the bladder for five days. The post-operative period was uncomplicated and the patient was discharged on the tenth post-operative day.

Pathological report (J. E. Morison): “The small diverticulum is lined in part by transitional epithelium and in part by squamous epithelium, but in great part the lining is deficient and there is a heavy non-specific inflammatory reaction. There are some follicular aggregates of lymphocytes which are usually taken to indicate an inflammatory reaction of considerable duration."

Follow-up after two months showed the patient to be symptomless and the vagina to be well healed.

\section{Case 2}

A married woman aged 37 had had three uncomplicated confinements and one abortion. There was no history of previous urinary trouble. She was referred to the antenatal clinic by her doctor, being approximately 38 weeks pregnant in her fifth pregnancy, with a painful swelling in the vagina. Vaginal examination revealed a very tender, firm swelling about $4 \mathrm{~cm}$. in diameter over the middle third of the urethra. There was a history of pain in the vagina and frequency of micturition of approximately six weeks'

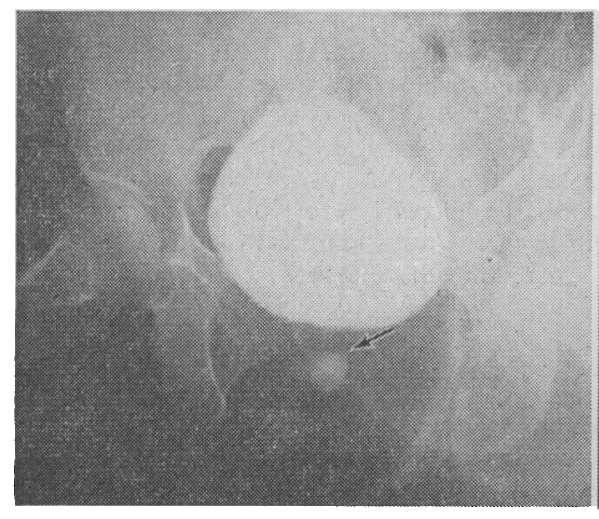

FIG. 1

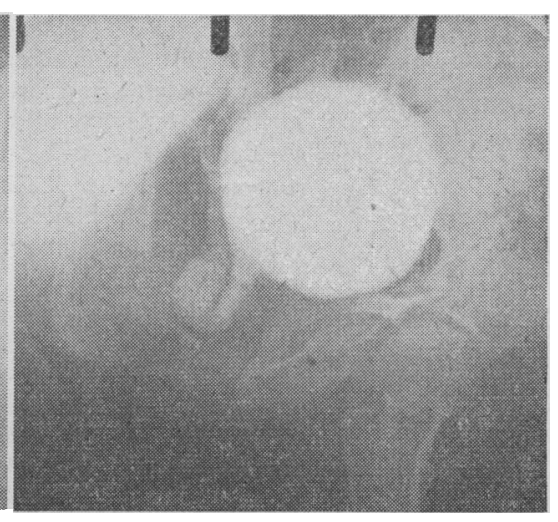

FIG. 2
FIG. 1.-Case 1. Micturating cystogram. FIG. 2.-Case 2. Micturating cystogram. trauma. sized cystocele. A Foley catheter was placed in the bladder for five days. The post-operative period was uneventful, and she was discharged on the 12th post-operative day.

A follow-up after two months showed her to be symptomless and the bladder well supported.

\section{Case 3}

A married woman aged 38 had had four uncomplicated confinements. She was admitted to the antenatal ward at term with a moderate pre-eclamptic toxaemia. Surgical induction was followed shortly by a normal delivery. While the patient was being examined prior to rupturing the membranes a well-defined fluctuant nontender swelling was noted on the anterior vaginal wall at the level of the upper third of the urethra. Compression produced a quantity of cloudy urine. She would not admit to any urinary symptoms or discomfort in the vagina. The suspected diverticulum was confirmed by micturating cystogram seven days after delivery. As the diverticulum was symptomless no treatment was recommended.

\section{Discussion}

The aetiology of diverticulum of the female urethra is controversial, and the statistical evidence to date does not indicate a higher incidence in a coloured population. The three theories postulated are those of infection, congenital abnormality, and

The symptomatology is similar to a cystitis, and the " feeling of inability to empty the bladder completely" and dribbling after micturition are practically diagnostic.

In diagnosis, still among the most important factors is a high degree of suspicion together with the taking of an adequate history. Inspection of the anterior vaginal wall may reveal the suspicion of a circumscribed swelling which can be confirmed by palpation. Pressure on the swelling may cause the escape of pus from the urethra. The immediate diagnosis may still not be obvious owing to the failure of the diverticulum to remain distended with urine. Urine analysis may show a catheter specimen to be sterile, while a midstream specimen may contain pus cells. The diverticulum may be demonstrated by the use of a urethral sound, while urethroscopy may reveal the ostium, though of ten it is obscured by granulation tissue or mucosal folds. Confirmatory evidence is best obtained by urethrography, using either the Taylor or the Roberts technique-the latter method, although satisfactory in the three cases recorded, is not always reliable with the smaller diverticula.

Of complications, infection presenting as either a periurethral abscess or recurrent urinary infection is the most common. Calculi $(20 \%)$ and stricture below the ostium occasionally occur. Only two cases of carcinoma have been reported, one an adenocarcinoma and the other of the transitional-cell variety. Urethro-vaginal fistulae, both spontaneous and following labour, are rare, but are frequent after surgical intervention.

The conservative approach to symptomless urethral diverticula may be adopted, employing periodic dilatation of the urethra and digital evacuation, together with antibiotic therapy ; or, where no treatment is necessary (Case 3 ), in the presence of symptoms it is generally agreed that surgical intervention is to be preferred. Two surgical procedures are in vogue-namely, packing the diverticulum with Oxycel gauze (Ellik, 1957) and complete surgical excision, both under antibiotic cover.

\section{Comment}

The three cases presented thus demonstrate the wide variety of symptoms which may be present in diverticula of the female
The diverticulum was dissected free with some difficulty owing to the presence of a chronic inflammatory reaction. An anterior colporrhaphy was then done because of the presence of a moderate- 
urethra. Case 1 had been investigated thoroughly on three different occasions but not diagnosed, and had the diverticulum not remained filled at the time of the recent examination the nature of the complaint would have again been missed. In Case 2 the problem was of treatment and not of diagnosis. A more conservative approach was employed in the first instance in view of the proximity of the forthcoming confinement. In retrospect it is felt that the use of Ellik's procedure would have been less difficult than surgical excision in the presence of the considerable chronic inflammatory reaction. Case 3 in particular would tend to favour the congenital origin of the lesion.

As three cases of urethral diverticulum were diagnosed by me in a period of two years the condition is obviously more common than I suspected. This knowledge should lead to a more frequent diagnosis of the lesion in the future.

\section{Summary}

Diverticula of the female urethra have often been reported in America in the past 20 years, while reference to them in the British literature is still scanty.

Three cases of diverticulum are presented and discussed.

A short summary of the aetiology, symptomatology, and treatment is presented.

\section{REFERENCES}

Ellik, M. (1957). 7. Urol. (Baltimore), 77, 243.

Fleming, J. B. (1959). Irish 7. med. Sci., p. 286. 303.

Hennessy, J. D. (1958). Brit. F. Urol., 30, 415.

Lane, V. (1957). Ibid., 29, 155.

Pinkerton, J. H. M. (1956). Ұ. Obstet. Gynaec. Brit. Emp., 63, 76.

\section{Preliminary Communications}

\section{Acute Pyogenic Meningitis Probably Due to Acanthamoeba sp.: a Preliminary Report}

\author{
[With Special Plate]
}

Brit. med. F., 1965, 2, 740-742

In 1961 a 9-year-old boy from Port Augusta, a country town in South Australia, died at the Adelaide Children's Hospital with a meningitis pathologically unremarkable except for the presence in the brain and meninges of large numbers of amoebae, morphologically distinct from Entamoeba histolytica. No pathogenic organisms were cultured from the cerebrospinal fluid or meningeal exudate, but the clinical record and laboratory investigations were considered to be characteristic in all other respects of acute bacterial meningitis.

In 1965 three further patients from the same district died in similar circumstances, and this report is a brief account of the clinical and pathological manifestations, with a hypothesis on the aetiology and pathogenesis of what we believe to be a previously undescribed disease.

\section{CAses 1, 2, and 3}

The clinical features of the first three patients, a 9-year-old boy and two girls both aged 8 years (Adelaide Children's Hospital Case Nos.: AU 992, AM 3871, and BD 2015), are so similar that they will be presented collectively. Before the onset of their fatal illness all were considered by their parents to be in good health, and no history of previous illnesses likely to be of aetiological significance was elicited by specific questioning. The first symptoms were noted on the fourth day before death, the children being described as lethargic and disinterested in their usual activities. On the following day all were feverish, obviously unwell, and complaining of severe headache, sore throat, and a blocked nose. Their local medical officers diagnosed an upper respiratory tract infection and started treatment with intramuscular and oral preparations of various antibiotics.

By the end of the third day, the patients' general condition having markedly deteriorated, with the onset of severe vomiting and an impaired level of consciousness, they were admitted to their local hospital with a provisional diagnosis of acute meningitis. This was confirmed by the finding of purulent cerebrospinal fluid on lumbar puncture, and was treated with glucose-saline fluids, chloramphenicol, penicillin, and sulphadiazine by the intravenous route. Deepening coma and signs of cardio-respiratory failure led to their transfer to the Adelaide Children's Hospital, where they all arrived moribund. Despite vigorous intravenous antibiotic and fluid therapy and attempts to relieve raised intracranial pressure they died shortly after admission.

Their cerebrospinal fluids contained predominantly neutrophil leucocytes varying from 400 to $8,000 / \mathrm{c} . \mathrm{mm}$., no micro-organisms were detected in stained smears, and cultures were unproductive of bacteria. However, all other features were so characteristic of fulminating bacterial meningitis that this was considered to be the nature of the disease, no other aetiological agent being seriously contemplated.

\section{CASE 4}

The clinical features of the fourth patient in this series, a 28-year-old man (Royal Adelaide Hospital Case No. 061501), are identical with those of the first three cases, except for the history of a sore throat and headache for two weeks before the onset of his major symptoms. He was transferred, in an equally moribund condition, from his local district hospital to the Royal Adelaide Hospital, where he died shortly after admission, death being considered due to acute meningitis of unknown aetiology.

\section{Pathology}

Post-mortem examinations were performed at four, two, five, and 48 hours after death (Adelaide Children's Hospital P.M. Nos: 8/61, $8 / 65$, and $18 / 65$; University of Adelaide Path. No. : 18208).

In all cases body development was normal, and no evidence of chronic disease was found in any organ. The gastro-intestinal tract, liver, and other abdominal viscera were not significantly abnormal. The lungs exhibited moderate oedema and vascular engorgement, with the addition in one instance of early bronchopneumonia. In three of the hearts the right-sided chambers were flabby and dilated, and the myocardium contained small foci of necrosis and inflammatory cell infiltration.

The skull and middle ears were normal. The brain was swollen only moderately, having flattened surface convolutions and partially obliterated sulci; there was no evidence of pressure coning. Meningeal veins were collapsed, superficial capillaries over the vertex engorged, and a few petechial haemorrhages were present in the pia mater and superficial cortical substance. A thin, creamy exudate was obvious in the basal subarachnoid cisterns, but elsewhere was not very apparent, except where it outlined a few of the sulcal grooves. In contrast to this appearance of rather minimal inflammation, the olfactory bulbs were very reddened, soft, and adherent by a mass of sticky exudate to the adjacent frontal cortex.

Microscopically the meningeal exudate consisted of about equal proportions of neutrophil leucocytes and chronic inflammatory cells, amongst which small, often degenerate amoebae were sparsely distributed. In the sulcal depths, and particularly in the VirchowRobin spaces, the amoebae were better preserved and more clearly 